\title{
Mycoplasma pneumoniae-Related Erythema Multiforme
}

\section{Mycoplasma pneumoniae Enfeksiyonuna Bağlı Gelişen Eritema Multiforme}

\author{
Nurhayat Yakut ${ }^{1}$, Eda Kepenekli Kadayıfçı ${ }^{1}$, Murat Aydın ${ }^{2}$, Halime Usta ${ }^{2}$ \\ ${ }^{1}$ Clinic of Pediatric, Pendik Training and Research Hospital, Marmara University School of Medicine, Istanbul, Turkey \\ ${ }^{2}$ Clinic of Pediatric Infectious Diseases, Pendik Training and Research Hospital, Marmara University School of Medicine, Istanbul, Turkey
}

Cite this article as: Yakut N, Kepenekli Kadayıfçı E, Aydın M, Usta H. Mycoplasma pneumoniae-related erythema multiforme. J Pediatr Inf 2018;12(3):e122

A five-year-old girl was admitted to the emergency room with complaints of fever, cough and itchy diffuse erythematous rash on her face and whole body. It was learned that the cough was present for about 2 weeks and that this condition was accompanied by fever and rashes that started on the feet one day before and spread to the whole body. Her physical examination revealed widespread, skin-pouling, erythematous, plaque-style rash on her face, trunk, arms and legs. (Figure 1A,B) The patient was diagnosed with erythema multiforme (EM). Mycoplasma pneumoniae PCR was negative in nasopharyngeal aspirate specimen, serum M. pneumoniae IgM was positive. The patient's fever and cough was improved with the treatment of 5 day azithromycin and local steroid. The patient was discharged after the rash was resolved.
A nine-year-old girl was admitted to the emergency room with complaints of cough and wounds in the mouth and lips. Her physical examination revealed diffuse mucosal erosions with fibrin in the mouth and edema on the lips (Figure 2). There was no skin rash. The patient was diagnosed with EM. M. pneumoniae PCR was positive in nasopharyngeal aspirate specimen, serum M. pneumoniae IgM was positive. The patient's clinical condition was recovered with 5 day azithromycin and local oral care and she was discharged.

EM is an acute hypersensitivity reaction that is usually self-limiting, affects the skin and mucous membranes. The most common infectious agent is herpes simplex virus, but adenovirus, cytomegalovirus, Epstein-Barr virus, hepatitis B virus, parapoxviruses (orf) and M. pneumoniae can cause EM.

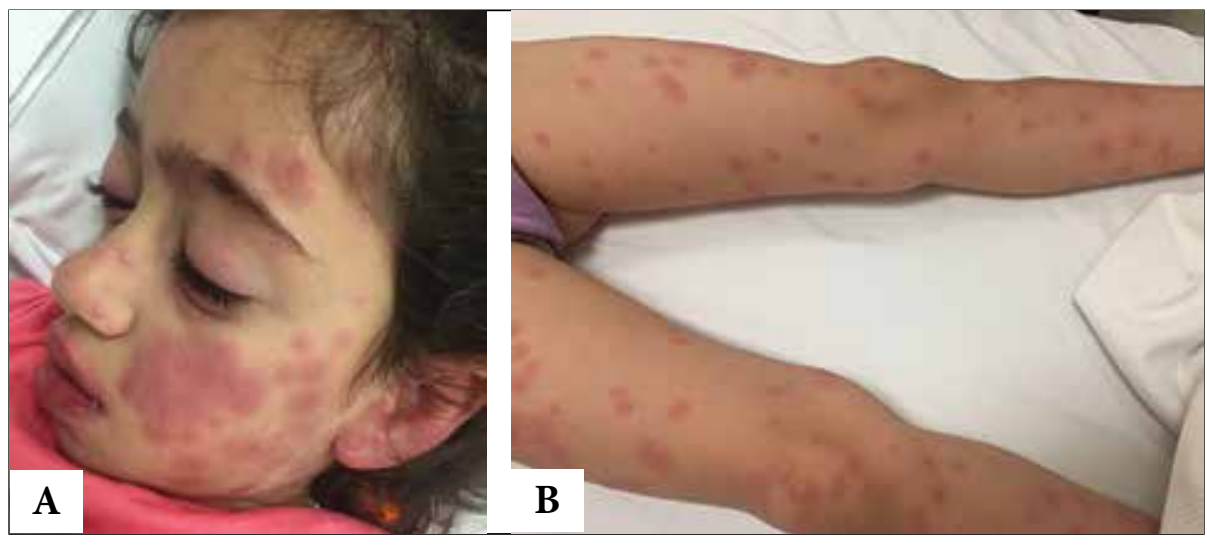

Figure 1(A,B). Skin-pouling, erythematous, plaque-style rash on her face and legs.

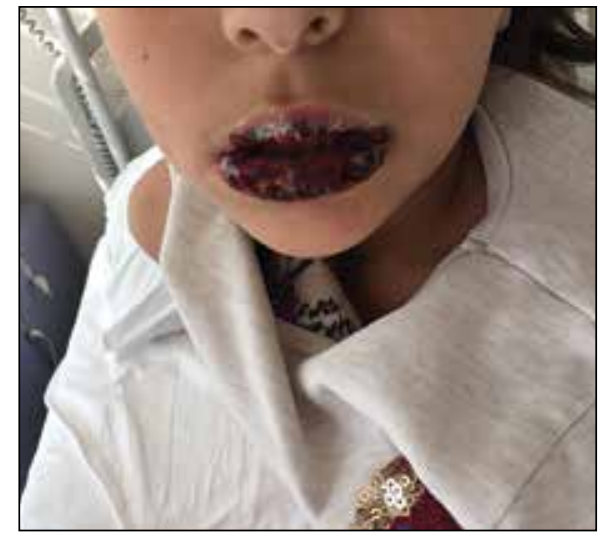

Figure 2. Edema and crusted lesions on the lips. 